\title{
Retrospective Analysis of Cerebrospinal Fluid Profiles in 228 Patients with Leptomeningeal Carcinomatosis : Differences According to the Sampling Site, Symptoms, and Systemic Factors
}

\author{
Youngbo Shim, M.D., ${ }^{1}$ Ho-Shin Gwak, M.D., Ph.D., ${ }^{2}$ Sohee Kim, M.S., ${ }^{3}$ Jungnam Joo, Ph.D., ${ }^{3}$ Sang-Hoon Shin, M.D., \\ Heon Yoo, M.D., Ph.D. ${ }^{4}$ \\ Department of Neurosurgery, ${ }^{1}$ Seoul National University College of Medicine, Seoul, Korea \\ Department of System Cancer Science, ${ }^{2}$ Graduate School of Cancer Science and Policy, Cancer Biostatistics Branch, ${ }^{3}$ Neuro-Oncology Clinic ${ }^{4}$ \\ National Cancer Center, Goyang, Korea
}

\begin{abstract}
Objective : Elevated cell counts and protein levels in cerebrospinal fluid (CSF) result from disease activity in patients with leptomeningeal carcinomatosis (LMC). Previous studies evaluated the use of CSF profiles to monitor a treatment response or predict prognosis. CSF profiles vary, however, according to the sampling site and the patient's systemic condition. We compared lumbar and ventricular CSF profiles collected before intraventricular chemotherapy for LMC and evaluated the association of these profiles with patients' systemic factors and LMC disease activity.

Methods : CSF profiles were retrospectively collected from 228 patients who underwent Ommaya reservoir insertion for intraventricular chemotherapy after a diagnosis of LMC. Lumbar samples taken via lumbar puncture were used for the diagnosis, and ventricular samples were obtained later at the time of Ommaya reservoir insertion. LMC disease activity was defined as the presence of LMC-related symptoms such as increased intracranial pressure, hydrocephalus, cranial neuropathy, and cauda equina syndrome.

Results : Cell counts (median : 8 vs. 1 cells $/ \mathrm{mL}$ ) and protein levels (median : 68 vs. $17 \mathrm{mg} / \mathrm{dL}$ ) significantly higher in lumbar CSF than in ventricular CSF $(p<0.001)$. Among the evaluated systemic factors, concomitant brain metastasis and previous radiation were significantly correlated with higher protein levels in the lumbar CSF ( $p=0.01$ and $<0.001$, respectively). Among the LMC disease activity, patients presenting with hydrocephalus or cauda equina syndrome showed higher lumbar CSF protein level compared with that in patients without those symptoms $(p=0.049$ and $p<0.001$, respectively). The lumbar CSF cell count was significantly lower in patients with cranial neuropathy $(p=0.046)$. The ventricular CSF cell counts and protein levels showed no correlation with LMC symptoms. Carcinoembryonic antigen (CEA), which was measured from ventricular CSF after the diagnosis in 109 patients, showed a significant association with the presence of hydrocephalus $(p=0.01)$.

Conclusion : The protein level in lumbar CSF indicated the localized disease activity of hydrocephalus and cauda equina syndrome. In the ventricular CSF, only the CEA level reflected the presence of hydrocephalus. We suggest using more specific biomarkers for the evaluation of ventricular CSF to monitor disease activity and treatment response.
\end{abstract}

Key Words : Cerebrospinal fluid $\cdot$ Leptomeningeal carcinomatosis $\cdot$ Lumbar $\cdot$ Ventricular.

\section{INTRODUCTION}

Leptomeningeal carcinomatosis (LMC) is a devastating complication that occurs in $1 \%$ to $15 \%$ of patients with non-hematologic cancer ${ }^{4,5,22)}$. Once LMC is established, the prognosis is poor, as the median overall survival is around 8 weeks ${ }^{12,17)}$.

One of the difficulties in intra-cerebrospinal fluid (CSF) che- motherapy for LMC is a lack of a quantitative measure of the treatment response. CSF cytology is frequently false negative, and meningeal enhancement appears as a streaky pattern on magnetic resonance imaging, the dimensions of which are hard to measure ${ }^{11,19)}$. As a result of the disease, patients with LMC have CSF profiles with elevated factors such as cell count, total protein, lactate dehydrogenase (LDH), and several tumor-specific anti-

- Received : July 4, 2016 • Revised : July 27, 2016 •Accepted : August 2, 2016

- Address for reprints : Ho-Shin Gwak, M.D., Ph.D.

Department of System Cancer Science, Graduate School of Cancer Science and Policy, National Cancer Center, 323 Ilsan-ro, Ilsandong-gu, Goyang 10408, Korea Tel : +82-31-920-1666, Fax : +82-31-920-2798, E-mail : nsghs@ncc.re.kr

- This is an Open Access article distributed under the terms of the Creative Commons Attribution Non-Commercial License (http://creativecommons.org/licenses/by-nc/3.0) which permits unrestricted non-commercial use, distribution, and reproduction in any medium, provided the original work is properly cited. 
gens. Many studies have tried to correlate those CSF profiles with the disease activity ${ }^{2,3,9,14,25,26)}$. The results have been inconsistent, however, likely because of small numbers of patients or different sampling sites and times. Some studies suggest that CSF profiles are influenced by the sampling site, systemic conditions, and primary cancer types ${ }^{7,18,24)}$. Hence, it is essential to evaluate the influence of different sampling sites and clinical characteristics on CSF profiles in order to use CSF profile monitoring as a predictor of LMC progression and treatment response.

Based on CSF flow physiology, ventricular CSF obtained from the frontal horn might be too far upstream to harbor the gross LMC-related CSF contents such as cancer cells and large proteins, whereas lumbar CSF could contain precipitates of those contents. Neither exact differences in CSF profiles due to the sampling site nor a guideline to evaluate LMC disease activity with CSF profiles has yet been proposed.

We analyzed the CSF profiles of a relatively large number of patients with LMC prior to treatment to determine whether 1) general clinical characteristics such as primary cancer type affect CSF profiles significantly and 2) CSF profiles differ between sampling sites (lumbar vs. ventricular) and which site better reflects LMC disease activity.

\section{MATERIALS AND METHODS}

This retrospective study obeys all the rules and regulations of clinical study regarding human subject protection and acquired Institutional Review Board approval (NCC-2014-0135).

\section{Study design}

We performed a retrospective analysis of 283 patients with LMC from solid cancer that received Ommaya reservoir insertion after the diagnosis of LMC for intraventricular chemotherapy at the National Cancer Center between 2003 and 2013. We excluded from the matched analysis patients who had only CSF cytology without CSF cell count and chemistry and those who underwent Ommaya insertion without lumbar puncture after diagnosis of LMC based only on magnetic resonance imaging. Matched lumbar and ventricular CSF samples were obtained from 228 patients.

\section{End results}

LMC disease activity was evaluated based on existence of each of three symptoms : 1) hydrocephalus, in patients presented with confused mentality and/or gait disturbance regardless of ventriculomegaly on neuroimaging, 2) cranial neuropathy, which was not provoked by any mass lesion other than LMC in neuroimaging study and 3) cauda equina syndrome was defined in patients having sacral hypesthesia, and lower extremity polyneuropathy. Increased intracranial pressure (ICP) was defined as ICP above $15 \mathrm{~mm} \mathrm{Hg}\left(20 \mathrm{~cm} \mathrm{H}_{2} \mathrm{O}\right)$ on Ommaya insertion and was considered to be one of signs of LMC disease activity.

\section{Evaluated parameters}

Basic clinical characteristics were investigated along with CSF profiles of cell count (total and others) and protein level. CSF glucose and $\mathrm{LDH}$ levels were also evaluated to control for bias from CSF infection or sample hemolysis. In patients having tumor makers elevated in previous work-up for primary cancer, the tumor-specific antigen carcinoembryonic antigen (CEA) were checked in the ventricular CSF of 109 patients after diagnosis of LMC without prospective protocol. Other tumor markers such as CA-125, HER-2 was also checked randomly in some patients based on primary physician's choice.

CSF samples were defined according to the time and site of sampling. Lumbar samples were obtained first via lumbar puncture and were used to make the initial diagnosis. Ventricular samples were obtained later at the time of Ommaya reservoir insertion for intraventricular chemotherapy.

\section{Statistical analysis}

CSF profiles were compared quantitatively between lumbar and ventricular samples using the Wilcoxon signed rank test. Associations between CSF profiles and LMC symptoms were analyzed using the Wilcoxon rank sum test. $p$-values $<0.05$ were considered significant. All calculations were performed using the R statistical software (version 5.1).

\section{RESULTS}

\section{Clinical characteristics of the patients}

The clinical characteristics of the 228 patients are summarized in Table 1 . The median age was 54 years (range : $23-82$ ). The majority of the patients had non-small cell lung cancer (77\%), while others had breast cancer (15\%), or small cell lung cancer or other primary cancers. Two-thirds of the patients had systemic disease with progression. Concomitant brain metastasis at the time of LMC diagnosis was found in 170 patients (75\%). Whole-brain radiation was given to 60 (26\%) of the patients either for parenchymal brain metastasis or with an expectation of improving LMC symptoms before intraventricular chemotherapy.

Headache with nausea and vomiting were the most common presenting symptoms (83\%), followed by hydrocephalus (confused mentality with gait disturbance) and cauda equina syndrome (26\% and 24\%, respectively). Cranial neuropathy presented in 23 patients $(10 \%)$.

\section{General description of CSF profiles in patients with LMC}

The mean total cell count in the lumbar CSF was 25.0 cells/ $\mathrm{cm}^{3}$ (standard deviation : \pm 47.3 ; range : $0-310$ ). The reference normal range was set at $\leq 5 \mathrm{cells} / \mathrm{cm}^{3}$. The distribution of the cell count had a leftward skew (median : $8 \mathrm{cells} / \mathrm{cm}^{3}$; third quartile : 25 cells $/ \mathrm{cm}^{3}$ ) (Fig. 1A). The distribution of the cell counts in the ventricular CSF was also skewed (mean : 10.4 cells $/ \mathrm{cm}^{3}$; standard deviation : \pm 44.2 ; range : 0-360; median : 1 cells $/ \mathrm{cm}^{3}$; third quartile $: 5$ cells $/ \mathrm{cm}^{3}$ ) (Fig. 1B). 
Table 1. Clinical characteristics of patients with LMC $(n=228)$

\begin{tabular}{|c|c|c|c|c|c|c|c|c|c|}
\hline \multirow{3}{*}{ Characteristics } & \multirow{3}{*}{$\begin{array}{c}\text { No. of } \\
\text { patients (\%) }\end{array}$} & \multicolumn{4}{|c|}{ Lumbar } & \multicolumn{3}{|c|}{ Ventricular } & \multirow[b]{3}{*}{$p$ value } \\
\hline & & Cell count & & Protein level & & Cell count & & Protein level & \\
\hline & & $\begin{array}{c}\text { Median } \\
\text { (range) }\end{array}$ & $p$ value & $\begin{array}{l}\text { Median } \\
\text { (range) }\end{array}$ & $p$ value & $\begin{array}{c}\text { Median } \\
\text { (range) }\end{array}$ & $p$ value & $\begin{array}{l}\text { Median } \\
\text { (range) }\end{array}$ & \\
\hline Gender & & & 0.34 & & 0.08 & & 0.17 & & 0.76 \\
\hline Male & $88(39)$ & $9(0-282)$ & & $73(21-717)$ & & $1(0-90)$ & & $17(7-155)$ & \\
\hline Female & $140(61)$ & $6.5(0-300)$ & & $63(17-1246)$ & & $0(0-360)$ & & $17(6-885)$ & \\
\hline Median age (range) & $54(23-82)$ & & 0.93 & & 0.87 & & 0.41 & & 0.30 \\
\hline$<60$ & $181(79)$ & $8(0-300)$ & & $67(20-1246)$ & & $1(0-360)$ & & $17(6-885)$ & \\
\hline$\geq 60$ & $83(36)$ & $7(0-160)$ & & $67.5(17-703)$ & & $0(0-40)$ & & $18(7-223)$ & \\
\hline Primary cancer & & & 0.66 & & 0.06 & & 0.77 & & 0.08 \\
\hline NSCLC & $175(77)$ & $8(0-300)$ & & $60(17-1246)$ & & $1(0-180)$ & & $17(6-885)$ & \\
\hline Small cell lung cancer & $6(3)$ & $10(2-282)$ & & $129(43-184)$ & & $0.5(0-90)$ & & $30.5(7-55)$ & \\
\hline Breast cancer & $35(15)$ & $5(0-140)$ & & $87(21-738)$ & & $1(0-360)$ & & $23(8-200)$ & \\
\hline Others & $12(5)$ & $3.5(0-260)$ & & $73.5(21-889)$ & & $1(0-20)$ & & $21(9-223)$ & \\
\hline Systemic disease status at LMC & & & 0.69 & & 0.17 & & 0.97 & & 0.82 \\
\hline NED & $9(4)$ & $5(2-30)$ & & $48(30-386)$ & & $1(0-20)$ & & $17(9-114)$ & \\
\hline $\mathrm{SD} / \mathrm{PR}$ & $68(30)$ & $7(0-175)$ & & $57.5(17-383)$ & & $1(0-79)$ & & $17(7-237)$ & \\
\hline Progress & $151(66)$ & $9(0-300)$ & & $76(17-1246)$ & & $0(0-360)$ & & $17(6-885)$ & \\
\hline Concomitant brain meta & & & 0.76 & & 0.01 & & 0.89 & & 0.13 \\
\hline Yes & $170(75)$ & $8.5(0-300)$ & & $77(17-1246)$ & & $1(0-360)$ & & $18(6-885)$ & \\
\hline No & $58(25)$ & $7(0-260)$ & & $52(21-889)$ & & $1(0-35)$ & & $16(6-128)$ & \\
\hline Previous whole-brain radiation & & & 0.178 & & $<0.001$ & & 0.43 & & 0.33 \\
\hline Yes & $60(26)$ & $10(0-282)$ & & $100(21-1246)$ & & $0(0-360)$ & & $20(6-200)$ & \\
\hline No & $168(74)$ & $7(0-300)$ & & $58(17-889)$ & & $1(0-180)$ & & $17(7-885)$ & \\
\hline
\end{tabular}

NSCLC : non-small cell lung cancer, LMC : leptomeningeal carcinomatosis, NED : no evidence of disease, SD : stable disease, PR : partial response

The mean protein level in the lumbar CSF was $134 \mathrm{mg} / \mathrm{dL}$ (standard deviation $: \pm 197$ ). The reference normal range was set to $0-60 \mathrm{mg} / \mathrm{dL}$. The distribution of protein levels had a leftward skew (median : $68 \mathrm{mg} / \mathrm{dL}$; range : 17-1246; third quartile : 124 $\mathrm{mg} / \mathrm{dL}$; Fig. 1C). The protein level in the ventricular CSF was distributed in a narrower range $(6-237 \mathrm{mg} / \mathrm{dL})$ with a median value of $17 \mathrm{mg} / \mathrm{dL}$. The mean and third-quartile protein levels in the ventricular CSF were the same at $29 \mathrm{mg} / \mathrm{dL}$ (standard deviation : \pm 33 ; Fig. 1D).

\section{Difference of CSF profiles according to the sample site}

We hypothesized that the 'initial' lumbar samples obtained downstream of the physiologic CSF flow would reflect LMC activity and that the 'pretreatment' ventricular CSF from the frontal horn would be too far upstream to reflect LMC activity. Grossly, all of the evaluated parameters were significantly higher in the lumbar CSF profiles than in the intraventricular CSF profiles $(p<0.001)$ (Fig. 2A, B). Individual analyses of the matched samples showed that 188 patients $(82 \%)$ had a higher cell count in the lumbar CSF than in the ventricular CSF (Fig. 2C). In terms of the protein level, 208 patients (94\%) had a higher protein level in the lumbar CSF than in the ventricular CSF (Fig. 2D).

\section{Influence of clinical characteristics and systemic conditions on CSF profiles}

We evaluated whether the clinical characteristics of the patients could be reflected in the CSF profiles (Table 1). Neither the cell count nor the protein level differed significantly according to gender, age ( $<60$ vs. $\geq 60$ ), systemic disease status, or presenting symptoms. Small cell lung cancer tended to be accompanied by higher protein levels compared with the other primary cancers, but the difference failed to reach statistical significance in either the lumbar or the ventricular CSF ( $p=0.06$ and 0.08 , respectively). Protein levels were significantly higher in the lumbar CSF from patients with concomitant brain metastases compared with those in the lumbar CSF from patients without brain metastases (median : 77 vs. $52 \mathrm{mg} / \mathrm{dL} ; p=0.01$ ). The patients who underwent whole-brain radiotherapy previously also showed significantly higher protein levels in the lumbar CSF than those who had not undergone (median : 100 vs. $58 \mathrm{mg} / \mathrm{dL} ; p<0.001$ ).

\section{Correlation between CSF profiles and LMC symptoms}

We found associations between the CSF profiles and some presenting LMC symptoms and signs (Table 2). Patients with hydrocephalus or cauda equina syndrome had significantly higher protein levels in the lumbar CSF compared with patients without those symptoms ( $p=0.049$ and $p<0.001$, respectively). Ven- 

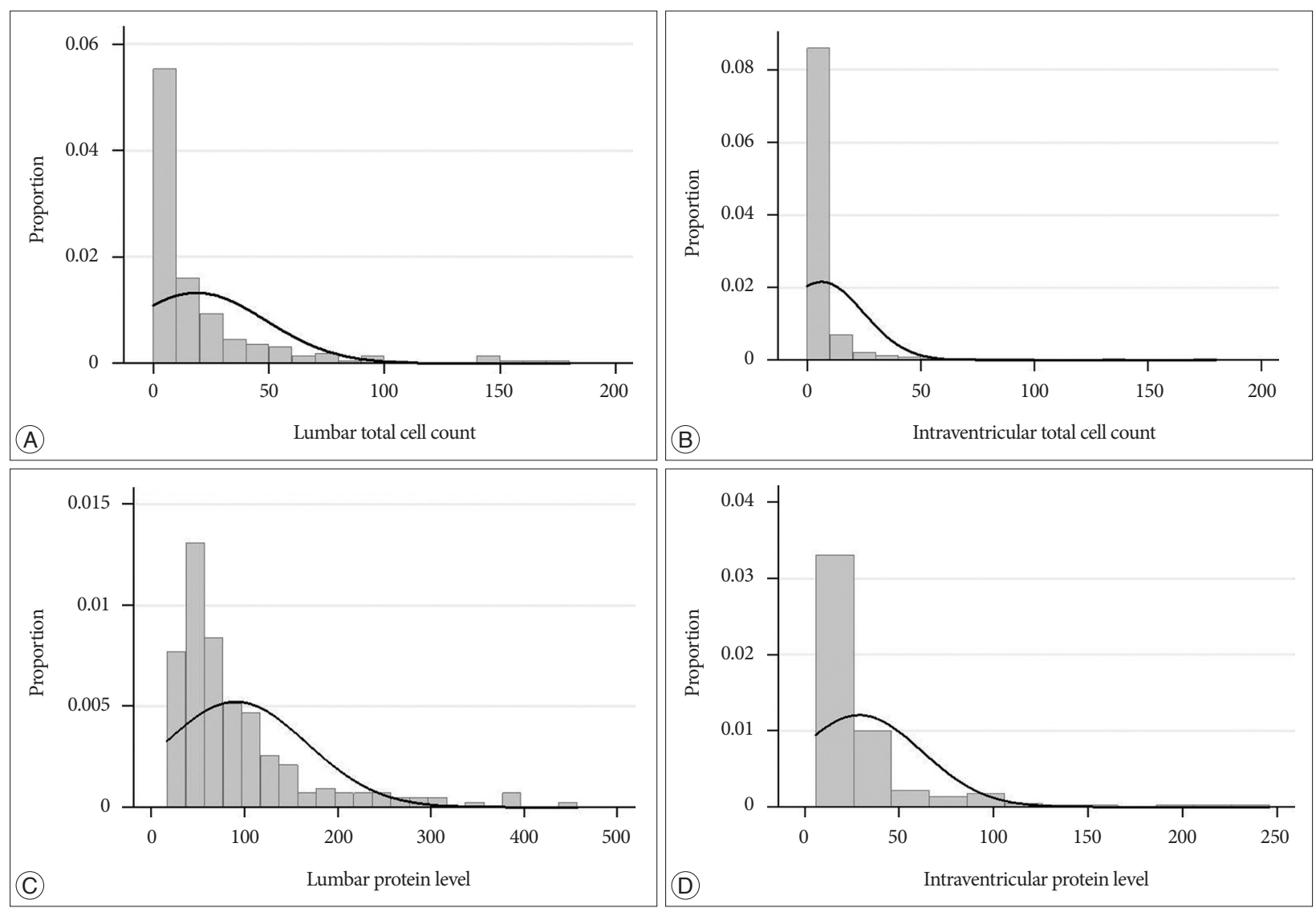

Fig. 1. Distribution of CSF profiles of total cell count ( $A$ and $B$ ) and protein level (C and $D)$ according to the different sampling site of lumbar ( $A$ and $C)$ and ventricular (B and D). CSF : cerebrospinal fluid.

tricular CSF protein levels did not show any significant association with any of the LMC symptoms. Paradoxically, patients with cranial neuropathy revealed lower cell counts in the lumbar CSF compared with patients without cranial neuropathy (median : 2 vs. 9 cells $/ \mathrm{cm}^{3} ; p=0.046$ ). None of the other LMC symptoms influenced the cell count in either the lumbar CSF or the ventricular CSF.

We re-examined the 'other' cell counts and performed each of the aforementioned comparisons and found no difference from the results based on the total cell counts (data not shown).

CEA levels were checked before and after the treatment in 109 patients and 98 patients among them were non-small lung cancer patients. We assumed CEA to be tumor-specific unlike the protein levels and cell counts, and CEA level were significantly higher in the ventricular CSF in patients with hydrocephalus than in patients without hydrocephalus $(p=0.01$ ). There was no correlation between CEA level and increased ICP or cauda equine syndrome.

\section{DISCUSSION}

Despite the limitations of a retrospective study, we evaluated matched-sample data, making it possible to compare CSF profiles between sampling sites. We assumed that the lumbar CSF profiles would be more precipitated and could better reflect the disease activity compared with the ventricular CSF profiles, because the ventricular CSF might be too far upstream of the CSF flow to reflect the LMC activity, which mainly occurs on the pial surface of the brain and spinal cord ${ }^{16)}$.

The lumbar CSF had significantly higher cell counts and protein levels than the ventricular CSF. The lumbar CSF protein levels were higher in patients with LMC symptoms such as hydrocephalus and cauda equina syndrome than in patients without those symptoms, whereas the ventricular CSF profiles were not correlated with any of the LMC symptoms. Paradoxically, the lumbar CSF cell counts were significantly lower in patients with cranial neuropathy than in those without cranial neuropathy. Chamberlain et al. ${ }^{7)}$ reported that CSF cytology results differ according to the sampling site and can therefore be used to localize LMC. In that report, the ventricular CSF of patients with cranial neuropathy had a three times greater chance of positive CSF cytology compared with the lumbar CSF of the same patients; however, the opposite was true in patients with spinal symptoms. We performed Ommaya reservoir insertion after the diagnosis of LMC via lumbar puncture, so we could not directly compare our data to that of Chamberlain et al. We consider our data to be in accordance with that of Chamberlain et al., however, as we assume that lower cell counts in the lum- 
bar CSF are associated with lower chances of positive CSF cytology. Our assumption that the ventricular CSF is 'too far upstream' is supported by the facts that the median cell count in the ventricular CSF $\left(1 \mathrm{cell} / \mathrm{cm}^{3}\right)$ was within the normal range and that $75 \%$ of the patients had $\leq 5$ cells $/ \mathrm{cm}^{3}$.

We hypothesize that the CSF flow disturbance, which can be
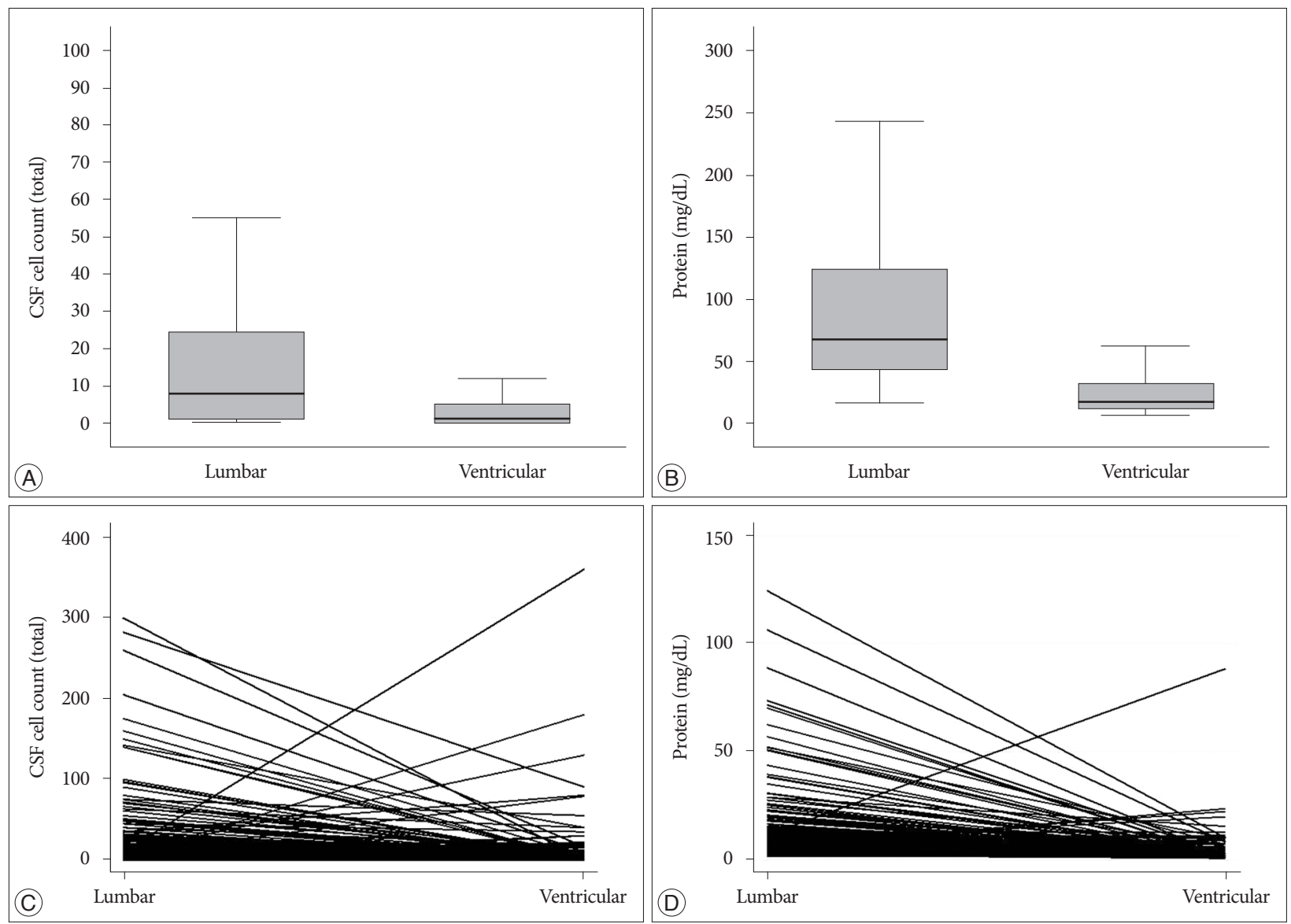

Fig. 2. Comparison of CSF cell count (A) and protein level (B) between lumbar and ventricular samples shows a significant difference ( $p<0.001$, both $A$ and $B$ ). The bold line is the median value, and the box represents quartile values. Individual solid lines connect lumbar and ventricular CSF profiles of individual patients in terms of cell count (C) and protein level (D). CSF : cerebrospinal fluid.

Table 2. Lumbar and ventricular CSF profiles correlated with LMC symptoms $(\mathrm{n}=228)$

\begin{tabular}{|c|c|c|c|c|c|c|c|c|c|c|}
\hline \multirow[b]{2}{*}{ LMC symptoms } & \multicolumn{4}{|c|}{ Lumbar CSF profiles } & \multicolumn{6}{|c|}{ Ventricular CSF profiles } \\
\hline & $\begin{array}{l}\text { Cell count } \\
\left(\text { cells } / \mathrm{cm}^{3}\right)\end{array}$ & $p$ value & $\begin{array}{l}\text { Protein } \\
(\mathrm{mg} / \mathrm{dL})\end{array}$ & $p$ value & $\begin{array}{l}\text { Cell count } \\
\left(\text { cells } / \mathrm{cm}^{3}\right)\end{array}$ & $p$ value & $\begin{array}{l}\text { Protein } \\
(\mathrm{mg} / \mathrm{dL})\end{array}$ & $p$ value & $\begin{array}{c}\text { CEA } \\
(\mathrm{n}=109)\end{array}$ & $p$ value \\
\hline Increased ICP (15 mm Hg) & & 0.57 & & 0.34 & & 0.47 & & 0.50 & & 0.40 \\
\hline Yes $(n=129)$ & $7(0-300)$ & & $75.5(17-703)$ & & $1(0-360)$ & & $18.5(7-223)$ & & $53(0-5098)$ & \\
\hline No $(n=99)$ & $8(0-205)$ & & $63(17-1246)$ & & $1(0-180)$ & & $17(6-885)$ & & $13(0-2822)$ & \\
\hline Hydrocephalus & & 0.62 & & 0.049 & & 0.58 & & 0.15 & & 0.01 \\
\hline Yes $(n=59)$ & $9(0-100)$ & & $92.5(25-1064)$ & & $1(0-180)$ & & $19(6-885)$ & & $96(0-4057)$ & \\
\hline No $(n=169)$ & $8(0-300)$ & & $61(17-1246)$ & & $1(0-360)$ & & $16(6-237)$ & & $12(0-5098)$ & \\
\hline Cauda equina syndrome & & 0.45 & & $<0.001$ & & 0.34 & & 0.11 & & 0.56 \\
\hline Yes $(\mathrm{n}=54)$ & $8(0-282)$ & & $118(35-1246)$ & & $0(0-90)$ & & $19(6-114)$ & & $25.3(0-4057)$ & \\
\hline No $(n=174)$ & $8(0-300)$ & & $59(17-889)$ & & $1(0-360)$ & & $16(6-885)$ & & $15(0-5098)$ & \\
\hline Cranial neuropathy & & 0.046 & & 0.54 & & 0.16 & & 0.44 & & \\
\hline Yes $(n=23)$ & $2(0-175)$ & & $68(17-1246)$ & & $0(0-79)$ & 0.16 & $16(8-237)$ & 0.44 & $8(0-2822)$ & 0.72 \\
\hline No $(n=205)$ & $9(0-300)$ & & $61(21-570)$ & & $1(0-360)$ & & $17(6-885)$ & & $20.8(0-5098)$ & \\
\hline
\end{tabular}

Representative numbers are median value and numbers in the parenthesis are ranges of observed values. CSF : cerebrospinal fluid, LMC : leptomeningeal carcinomatosis, ICP : intracranial pressure, CEA : carcinoembryonic antigen 
found in more than $50 \%$ of patients with $\mathrm{LMC}^{5)}$, could bring the particles (cells and proteins) floating in the CSF back to the ventricle. In our study, 59 patients presented hydrocephalus symptoms, which suggest CSF flow disturbance. Although the cell counts and gross protein levels in those patients were not higher than those in the patients without hydrocephalus, the levels of CEA, a cancer-specific antigen, were significantly higher in the ventricular CSF of patients with hydrocephalus. We could not tell why the cell counts and gross protein levels failed to show significant elevation despite the presence of CSF flow disturbance while the CEA level was significantly elevated. It might be that a relatively light particle is more likely to float back to the ventricle than the heavier cancer cells or immune cells. We assume that the pathophysiology of hydrocephalus in LMC (communicating hydrocephalus) occurs mainly on the pial surface or arachnoid granulation outside the ventricle in a way to block the CSF absorption, so we consider the elevated CSF CEA level to be more likely the result of CSF backflow or stasis than the result of LMC activity inside the ventricle. Similar results can be found in the study of Nakagawa et al. ${ }^{20)}$. They compared the ventricular and lumbar CSF levels of beta-glucuronidase and polyamines in patients with LMC. They found that both factors were lower in the ventricular CSF than in the lumbar CSF, with the difference in a range of $17-77 \%$.

Although the elevated lumbar CSF protein levels in patients with hydrocephalus or cauda equina syndrome, correlate the prognostic meaning is beyond the scope of this study. The presence of hydrocephalus or cauda equina syndrome is considered a negative prognostic factor in general ${ }^{6,10)}$, and the conclusions based on elevated CSF protein levels in patients with LMC vary from study to study. Clamon et al. ${ }^{8)}$ studied the lumbar CSF profiles of 22 patients with LMC from breast cancer and noted that the CSF protein level was not a significant predictor. Balm et al. ${ }^{2)}$ suggested that CSF protein elevation at presentation was an independent negative predictor in an analysis of 126 patients with cytologically confirmed LMC from various primary cancers. In contrast, Boogerd et al. ${ }^{3)}$ reported that a more than 'moderately-elevated' CSF protein level was more predictive of better outcomes compared with a 'mildly-elevated' protein level $(0.5-1.0 \mathrm{~g} / \mathrm{L})$ in an analysis of 58 patients with LMC from breast cancer. Hitchins et al. ${ }^{15)}$ studied 44 patients with breast cancer and reported a better response to the therapy in patients with elevated protein levels $(>0.50 \mathrm{~g} / \mathrm{dL})$.

The sampling site (lumbar vs. ventricular) and time might affect the CSF profiles significantly, but most previous studies did not examine those factors. Herrlinger et al. ${ }^{14)}$ studied the CSF profiles of 155 patients with LMC from various cancers including primary brain tumor, lymphoma, leukemia, and solid systemic cancers. They performed intrathecal chemotherapy rather than intraventricular chemotherapy and analyzed CSF samples taken only at presentation. Their CSF samples were thus comparable to our lumbar CSF samples and indicated that elevated protein and $\mathrm{LDH}$ levels were independent negative prognostic factors ${ }^{14)}$. There are few published analyses of pretreatment ventricular CSF profiles outside of this study. The monitoring of ventricular CSF is important, because most intrathecal chemotherapy is terminated at relatively short rounds, and the intraventricular reservoir is a safe and solid site for CSF sampling ${ }^{13,21)}$.

Recently, many authors have expressed doubt that CSF cell counts or gross protein levels are specific enough to reflect cancer cell activity, suggesting instead that they are passive garbage of LMC rather than active metabolites. Efforts are underway to find a CSF biomarker from cancer-specific microRNA or metabolites that is an active initiator or specific byproduct of $\mathrm{LMC}^{1,23)}$. We agree with those research trends, as we found that gross CSF profiles of cell counts and protein levels are poor indicators of LMC activity, especially when sampled from the ventricle.

\section{CONCLUSION}

Differences in CSF profiles according to clinical characteristics and sampling site suggest that lumbar CSF protein levels reflect LMC disease activity, whereas the ventricular CSF profiles do not. The elevated CEA levels in the ventricular CSF of patients with hydrocephalus encourage us to develop a specific ventricular CSF biomarker for the purpose of predicting prognosis or monitoring treatment response with a careful review of physiologic CSF flow.

\section{- Acknowledgements}

This work was supported by a grant (NCC-1511000-2) from the National Cancer Center, Korea.

\section{References}

1. An YJ, Cho HR, Kim TM, Keam B, Kim JW, Wen H, et al. : An NMR metabolomics approach for the diagnosis of leptomeningeal carcinomatosis in lung adenocarcinoma cancer patients. Int J Cancer 136 : 162 171,2015

2. Balm M, Hammack J : Leptomeningeal carcinomatosis. Presenting features and prognostic factors. Arch Neurol 53 : 626-632, 1996

3. Boogerd W, Hart AA, van der Sande JJ, Engelsman E : Meningeal carcinomatosis in breast cancer. Prognostic factors and influence of treatment. Cancer 67 : 1685-1695, 1991

4. Bruna J, González L, Miró J, Velasco R, Gil M, Tortosa A; Neuro-Oncology Unit of the Institute of Biomedical Investigation of Bellvitge : Leptomeningeal carcinomatosis : prognostic implications of clinical and cerebrospinal fluid features. Cancer 115 : 381-389, 2009

5. Chamberlain MC : Leptomeningeal metastasis. Curr Opin Oncol 22 : 627-635, 2010

6. Chamberlain MC : Radioisotope CSF flow studies in leptomeningeal metastases. J Neurooncol 38 : 135-140, 1998

7. Chamberlain MC, Kormanik PA, Glantz MJ : A comparison between ventricular and lumbar cerebrospinal fluid cytology in adult patients with leptomeningeal metastases. Neuro Oncol 3 : 42-45, 2001

8. Clamon G, Doebbeling B : Meningeal carcinomatosis from breast cancer : spinal cord vs. brain involvement. Breast Cancer Res Treat 9 : 213217, 1987

9. Fizazi K, Asselain B, Vincent-Salomon A, Jouve M, Dieras V, Palangie T, 
et al. : Meningeal carcinomatosis in patients with breast carcinoma. Clinical features, prognostic factors, and results of a high-dose intrathecal methotrexate regimen. Cancer 77 : 1315-1323, 1996

10. Glantz MJ, Hall WA, Cole BF, Chozick BS, Shannon CM, Wahlberg L, et al. : Diagnosis, management, and survival of patients with leptomeningeal cancer based on cerebrospinal fluid-flow status. Cancer 75 : 29192931, 1995

11. Glass JP, Melamed M, Chernik NL, Posner JB : Malignant cells in cerebrospinal fluid (CSF) : the meaning of a positive CSF cytology. Neurology 29 : 1369-1375, 1979

12. Grossman SA, Krabak MJ : Leptomeningeal carcinomatosis. Cancer Treat Rev 25 : 103-119, 1999

13. Gwak HS, Lee CH, Yang HS, Joo J, Shin SH, Yoo H, et al. : Chemoport with a non-collapsible chamber as a replacement for an Ommaya reservoir in the treatment of leptomeningeal carcinomatosis. Acta Neurochir (Wien) 153 : 1971-1978; discussion 1978, 2011

14. Herrlinger U, Förschler H, Küker W, Meyermann R, Bamberg M, Dichgans J, et al. : Leptomeningeal metastasis : survival and prognostic factors in 155 patients. J Neurol Sci $223: 167-178,2004$

15. Hitchins RN, Bell DR, Woods RL, Levi JA : A prospective randomized trial of single-agent versus combination chemotherapy in meningeal carcinomatosis. J Clin Oncol 5 : 1655-1662, 1987

16. Hladky SB, Barrand MA : Mechanisms of fluid movement into, through and out of the brain : evaluation of the evidence. Fluids Barriers CNS 11 : 26,2014

17. Jayson GC, Howell A : Carcinomatous meningitis in solid tumours. Ann Oncol 7 : 773-786, 1996

18. Kaplan JG, DeSouza TG, Farkash A, Shafran B, Pack D, Rehman F, et al. :
Leptomeningeal metastases : comparison of clinical features and laboratory data of solid tumors, lymphomas and leukemias. J Neurooncol 9 : 225-229, 1990

19. Lin NU, Lee EQ, Aoyama H, Barani IJ, Barboriak DP, Baumert BG, et al. : Response assessment criteria for brain metastases : proposal from the RANO group. Lancet Oncol 16 : e270-e278, 2015

20. Nakagawa H, Kubo S, Murasawa A, Nakajima S, Nakajima Y, Izumoto S, et al. : Measurements of CSF biochemical tumor markers in patients with meningeal carcinomatosis and brain tumors. J Neurooncol 12 : 111120, 1992

21. Park JH, Kim YJ, Lee JO, Lee KW, Kim JH, Bang SM, et al. : Clinical outcomes of leptomeningeal metastasis in patients with non-small cell lung cancer in the modern chemotherapy era. Lung Cancer 76 : 387-392, 2012

22. Taillibert S, Laigle-Donadey F, Chodkiewicz C, Sanson M, Hoang-Xuan $\mathrm{K}$, Delattre JY : Leptomeningeal metastases from solid malignancy : a review. J Neurooncol 75 : 85-99, 2005

23. Teplyuk NM, Mollenhauer B, Gabriely G, Giese A, Kim E, Smolsky M, et al : MicroRNAs in cerebrospinal fluid identify glioblastoma and metastatic brain cancers and reflect disease activity. Neuro Oncol 14 : 689700,2012

24. Twijnstra A, Ongerboer de Visser BW, van Zanten AP : Diagnosis of leptomeningeal metastasis. Clin Neurol Neurosurg 89 : 79-85, 1987

25. Wasserstrom WR, Glass JP, Posner JB : Diagnosis and treatment of leptomeningeal metastases from solid tumors : experience with 90 patients. Cancer 49 : 759-772, 1982

26. Yap HY, Yap BS, Rasmussen S, Levens ME, Hortobagyi GN, Blumenschein GR : Treatment for meningeal carcinomatosis in breast cancer. Cancer $50: 219-222,1982$ 